\title{
SLOW FASHION E O PRODUTO DE MODA COM ENFOQUE NO USUÁRIO
}

\author{
Maicon Douglas Livramento Nishimura \\ Universidade Federal de Santa Catarina \\ maiconnishimura@yahoo.com.br \\ Leila Amaral Gontijo \\ Universidade Federal de Santa Catarina \\ leila.gontijo@ufsc.br
}

Resumo: Slow fashion, um movimento que tem ganhado atenção no mercado de moda, possui como principal objetivo a conscientização da redução do ritmo produtivo do fast fashion a fim de obter um conceito de produto sustentável. Por meio de uma peça de vestuário produzida em pequena escala, com alta durabilidade e de princípios sustentáveis é possível agregar valor e gerar diferenciação de mercado. E, ao se apropriar da ideia de produção em pequena escala, pode-se buscar a solução para outro problema enfrentado que vai além da oferta desenfreada, a dificuldade de alinhamento do produto às questões de usabilidade que se refere à antropometria e sua contribuição na melhoria das modelagens. Muito se questiona no mercado e na academia sobre as dificuldades de uniformização e aderência das empresas à uma tabela de medidas quando o assunto é vestuário. A partir de uma revisão bibliográfica, busca-se correlacionar o slow fashion e uma proposta de análise antropométrica voltada ao usuário.

Palavras-chave: Slow Fashion, Mercado, Usuário.

\begin{abstract}
Slow fashion, a movement that has gained attention in the fashion market, has as main objective the awareness of reducing the productive rhythm of fast fashion in order to get a concept of sustainable product. Through a garment produced on a small scale, with high durability and sustainable principles can add value and create market differentiation. In addition, by appropriating the idea of small-scale production, can seek the solution to another problem facing the market that goes beyond the unrestrained supply, product alignment difficult to usability issues in relation to anthropometry. Questions remain on the market and academia about the difficulties of standardization and adherence of companies to a table measures when it comes to clothing. From a literature review, seeks to correlate the fashion slow and a proposal for anthropometric analysis focused on the user.
\end{abstract}

Keywords: Slow Fashion, Market, User. 


\section{INTRODUÇÃO}

A massificação do vestuário, produto de análise da prospecção de tendência de moda, foi impulsionada com o surgimento das lojas de departamento que se tornavam lucrativas por apresentarem novidades constantemente. Esse ritmo de mercado se intensificou com a globalização e com o avanço do marketing, pois, a partir dessa disciplina, pode-se compreender o comportamento do consumidor e antecipar o que ele deseja sem ao menos perceber.

Dessa forma, com a produção em massa dos produtos de moda e, uma consequente redução do custo e do preço final, tornou-se acessível consumir e a demanda por novidade aumentou no decorrer dos anos. Porém, a maneira como se organizou a dinâmica de produção causa preocupação e põe organizações, governos e a sociedade em alerta. Condições precárias de trabalho, rotinas intensas e exaustivas, trabalho escravo são algumas notícias deflagradas em relação à realidade do mundo da moda.

O recente documentário "The True Cost" (2015), dirigido por Andrew Morgan, retrata como são os bastidores do mercado de moda do século XXI. Com o intuito de reduzir custos e se aproveitar de legislações frágeis, empresas do mundo todo terceirizam suas produções em países em desenvolvimento. Essa migração do processo produtivo tem gerado passivos sociais que são de desconhecimento da população que não vive a realidade local.

No sentido aposto à produção em massa e em direção aos movimentos que propõem um mercado de moda sustentável, surge o slow fashion. Esse novo sistema é pautado no ideal da redução da velocidade do processo produtivo, de consumo, da preocupação com o meio ambiente e do retorno social. Para Fabri e Rodrigues (2015), esse novo sistema ainda conta com o uso de técnicas tradicionais e valoriza materiais e mercados regionais.

Assim como na moda, outros setores têm dado atenção ao aprimoramento do seu produto a fim de agregar valor. Exemplo disso está na gastronomia com a disseminação de comidas tipicamente do segmento fast food, como os hambúrgueres que ganharam um caráter mais sofisticado. Dessa forma, na alimentação como no produto de moda, consegue-se atingir um público que busca diferenciação e está disposto a pagar um pouco a mais por isso.

De maneira simplificada, Kotler e Keller (2012, p.227) comentam que

As empresas não podem atender a todos os clientes em mercados amplos
ou diversificados. Mas podem dividir tais mercados em grupos de
consumidores ou segmentos com diferentes necessidades e desejos. Uma
empresa precisa, então, identificar os segmentos de mercado em que
poderá atender com eficácia.

Baseado nisso, o empresário que busca competir em um mercado precisa compreender fundamentalmente o público a quem se dirige. Ao aferir o produto de vestuário como dinâmico, dado o seu caráter efêmero devido às tendências de moda que são limitadas por um calendário estacional, primavera/verão e outono/inverno, as empresas precisam traçar estratégias alinhadas nesse mesmo ritmo. Silveira (2008) levanta que as empresas do setor de vestuário têm buscado a segmentação de mercado como alternativa para melhor atender de forma pontual determinado grupo de consumidores e, dessa forma, torna o produto mais competitivo em preço e outros conceitos de moda e design. 
Ao se falar em produto de moda é necessário pensar em quais atributos podem sofrer modificações e/ou aperfeiçoamentos para que se tenha um produto diferenciado e destacado em relação à concorrência. Como base em critérios de usabilidade, pode-se pensar na modelagem, no tipo de material, em texturas e no design da peça. Entretanto, se considerar a usabilidade do produto, no que se refere ao conforto, a questão do ajustamento da peça ao corpo é requisito fundamental e bastante complexo de se atender de forma massificada.

Bazán et al (2010) sugerem que para minimizar a dificuldade de encontrar roupa para determinado biótipo seja adotado um sistema de segmentação de medidas, ou seja, obtenha-se uma média antropométrica de uma região a fim de obter maior fidedignidade entre as informações do corpo do usuário e as tabelas de medidas geradas.

Baseado nessas ideias, foi feita uma revisão bibliográfica para levantar informações na literatura acerca da agregação de valor ao produto de moda, tendo como referência o conforto derivado da modelagem, com o intuito de buscar uma relação com o slow fashion. Desse modo, a partir de uma abordagem qualitativa e de caráter exploratório, objetiva-se correlacionar o slow fashion e uma análise antropométrica voltada ao usuário, conforme metodologia proposta por Gil (2002).

\section{DESENVOLVIMENTO}

\subsection{Moda e slow fashion}

A roupa deixa de ser eternizada como indumentária e se constrói na temporalidade à medida que a sociedade muda suas próprias relações de poder. Lipovetsky (1989) aborda que a moda é efêmera devido à mutabilidade do sistema social no qual os indivíduos estão inseridos. E é nesse ambiente em que se constroem as relações e que a roupa ganha destaque como objeto de significação. Ainda, sob o olhar do mesmo autor, a moda serve de espaço para a socialização, por meio do agrupamento de iguais, e diferenciação, no momento em que determinadas pessoas buscam se destacar dentro de um grupo e passam a servir de referência para os demais.

No sentido de propor diferenciação, Worth estabeleceu novos padrões para o universo da moda e ficou marcado na história como precursor da alta costura. Para atender a uma burguesia em ascensão, no outono de 1857, Worth funda a sua maison, o marco inicial para a alta costura, e estabelece uma sistemática que passa a disciplinar o mercado de moda como, por exemplo, a instituição de um calendário de lançamento de coleções baseado em estações, primavera/verão e outono/inverno (LIPOVESTKY, 1991).

Como parte do processo de transformação da sociedade, a alta costura perdeu, gradativamente, espaço para o prêt-à-porter e este assumiu um papel equivalente à produção em massa no período pós-guerra (RECH, 2006). Nesse contexto, em que as maisons lucram pouco com as roupas e mais com os produtos licenciados, surge a nova expressão que permeia a alta costura e a produção industrial massificada.

É em 1949 que J. C. Weill lança na França a expressão "prêt-à-porter" tirada da fórmula americana ready to wear, e isso a fim de libertar a confecção de sua má imagem de marca. À diferença da confecção tradicional, o prêt-àporter engajou-se no caminho novo de produzir industrialmente roupas acessíveis a todos, e ainda assim "moda", inspiradas nas últimas tendências 
do momento. Enquanto a roupa de confecção apresentava muitas vezes um corte defeituoso, uma falta de acabamento, de qualidade e de fantasia, o prêt-à-porter quer fundir a indústria e a moda, quer colocar a novidade, o estilo e a estética na rua (LIPOVESTKY, 1991, p.109).

Então é entre a alta costura francesa, o ready to wear americano que, posteriormente, também foi adotado pela França como prêt-à-porter, e a confecção tradicional que se estabeleceu os modos de fabricação do vestuário de moda. Ressaltase que a exclusividade, a personalização, o maior custo e, consequentemente, o maior preço caminham no sentido da alta costura para a confecção tradicional. Ou seja, a alta costura apresenta produtos com alto valor agregado e preço elevado em contraposição à confecção tradicional que se equilibra na tríade da vantagem estratégica de Porter (1991), preço, enfoque e diferenciação para se manter no mercado de maneira competitiva.

O presente sistema de moda dominante, o fast fashion, tem sua base na confecção tradicional que busca referências no prêt-à-porter para replicar, com preço baixo e alta velocidade, produtos às massas. É o varejo que tem importante papel para a intermediação entre indústria e cliente na venda de roupas, mas com a ascensão da internet e as vendas por esse meio, o e-commerce, ganhou espaço e permitiu que a moda se tornasse um mercado mais global do que era no passado, quando as tendências francesas eram levadas de navio para os Estados Unidos.

Entretanto, frente às consequências desenfreadas do ritmo acelerado do fast fashion, surge um sistema que vem questionar a atual proposta do mercado de moda, o slow fashion. Esse termo foi cunhado do movimento slow food, fundado por Carlos Petrini na Itália, em 1986, que tinha a proposta de apreciação do alimento pautada na consciência e responsabilidade do preparo e da escolha dos insumos (FLETCHER, 2007).

Dentro da realidade da moda, a proposta também é de consciência e responsabilidade no ciclo de vida do produto e do processo produtivo de moda. A ideia do movimento slow fashion foi de Kate Fletcher, consultora de design sustentável (FASHIONISTA, 2012). Kate já possuía um alinhamento para a sustentabilidade na moda antes mesmo de sugerir o termo slow fashion, que o define como "a moda vista a partir de um diferente ponto de partida para o crescimento, o consumo responsável na moda" (FLETCHER, 2012).

Ainda, de acordo com a precursora do movimento, o sistema é o futuro para o setor do vestuário, desde a indústria têxtil até as confecções, e uma oportunidade de negócio que busca a igualdade por meio do respeito para com os colaboradores e consumidores (FLETCHER, 2007). Ela ressalta também que essa mudança visa a qualidade em detrimento da quantidade e que isso possui um custo financeiro, mas também resulta em valor agregado que vai além das características do produto, preserva a pessoa que trabalha na confecção da peça e também proporciona uma maior interação entre os indivíduos envolvidos na cadeia de produção.

Fabri e Rodrigues (2015) apontam que as características do slow fashion e do fast fashion levam a acreditar em uma oposição de propostas. Contudo, Flecther (2007) comenta que não são opostos, são sistemas diferentes. Isso pode ser confirmado quando se analisa o ambiente explorado por cada um. Por exemplo, o foco em um mercado local e não global ou a produção em pequena escala ao invés de uma grande produção. 


\subsection{Segmentação de mercado e a agregação de valor ao produto de moda}

Das resultantes geradas pelo sistema slow fashion, a segmentação de mercado pode ser observada como inevitável. Seja pelo fato da necessidade de diminuir a abrangência de mercados a serem atendidos, globais para locais, seja por atingir um público que compartilha da mesma filosofia ou pelo custo que o valor agregado ao produto vai acrescer no preço final.

Kotler e Keller (2012) definem que para uma segmentação de mercado efetiva é necessário satisfazer cinco critérios: mensuração, substancialidade, acessibilidade, diferenciação e acionabilidade. Isto é, as características do segmento devem ser possíveis de mensurar, o segmento precisa ser grande, rentável e o mais homogêneo que se conseguir alcançar, é necessário poder abranger e atender o segmento, o mix de marketing precisa responder de forma diferente à diversos segmentos, além de que deve ser viável desenvolver programas efetivos para atingir o segmento.

Ao recorrer à definição do sistema slow fashion e verificar a pontualidade de seus conceitos, nota-se que dentro de uma proposta de segmentação de mercado como a apresentada anteriormente, há um mercado bastante específico a ser explorado, pelo menos na realidade brasileira. Afinal, mercados restritos costumam ser explorados por empresas menores a fim de evitar concorrer com empresas de grande porte, já que são de pouco ou nenhum interesse estratégico para essas. (KOTLER E KELLER, 2012). Nesse sentido,

Empresas com pequenas participações no mercado total podem ser extremamente lucrativas graças a uma estratégia de nicho inteligente. Essas empresas tendem a oferecer alta qualidade, cobrar preços premium, conseguir custos de fabricação mais baixos e formar uma cultura e uma visão corporativas muito fortes (KOTLER E KELLER, 2012, p.328).

Com esse afunilamento, a diferenciação ganha atenção no processo de agregar valor ao produto, porque permite uma identidade à marca, nesse caso, ao ideal de consciência e responsabilidade. Para se diferenciar um produto, pode-se trabalhar na forma, características, qualidade de desempenho, qualidade de conformidade, durabilidade, confiabilidade, facilidade de reparo ou estilo (KOTLER E KELLER, 2012).

Em uma realidade segmentada e apoiado na diferenciação como instrumento, o objetivo dentro de um mercado competitivo é agregar valor ao produto. Kotler e Keller (2012, p.35) apresentam que "em uma economia extremamente competitiva, com compradores cada vez mais racionais diante de uma abundância de opções, uma empresa só pode vencer ao ajustar o processo de entrega de valor e selecionar, proporcionar e comunicar um valor superior". Para os autores, o processo de entrega de valor consiste em selecionar o valor baseado na segmentação de mercado e posicionamento do produto, em seguida, fornecer o valor por meio das características específicas do produto, do preço ou distribuição e, por fim, comunicar o valor por intermédio de ferramentas promocionais. Eles apontam que cada etapa soma custos ao processo.

\subsection{A antropometria e o usuário}

Se consideramos o conforto como um diferencial que agrega valor ao produto, os estudos antropométricos que servem de base para a definição da modelagem a ser aplicada nos produtos, podem ganhar uma importante dimensão nos estudos sobre este valor a ser considerado slow fashion. 
Pessoas com medidas disformes da média populacional não conseguem ser atendidas pela indústria do vestuário (FEGHALI, SCHMID E LIMA, 2008). Porém, é de senso comum, que grande parte da população sofre com a mesma dificuldade de encontrar peças de vestuário no varejo. Questiona-se, então, se as empresas projetam seus produtos focados no usuário.

Com o intuito de fornecer conforto, a indústria precisa atender requisitos de usabilidade física com base em análise antropométrica. Silveira (2008) aborda que, com ferramentas ergonômicas aplicadas à modelagem do vestuário, tendo em vista materiais e os métodos de acabamento da peça, pode-se obter a funcionalidade da roupa e aponta a necessidade do conhecimento de dimensões corpóreas para a relação direta projeto e usuário.

A falta de informações de medidas corporais do público-alvo traz complicações na elaboração da peça de roupa e resulta na falta de conformidade entre marcas ou, até, dentro de uma mesma empresa (BAZÁN et al, 2010). Na pesquisa realizada por esses autores, "Antropometria para a confecção - dados de Cianorte e região", sugerese a partir de um levantamento antropométrico local, a necessidade desse tipo de dado para a indústria, uma vez que não há um estudo antropométrico representativo no Brasil.

Em "As medidas do homem e da mulher: fatores humanos em design", de Alvin R. Tilley (2005) da Henry Dreyfuss Associados, apresenta que informações sobre medidas padronizadas são importantes para a elaboração de projetos de design, no entanto, é fundamental o teste do produto com pessoas reais, afinal, é difícil de aferir conforto e sensações com base apenas em dados.

\section{CONCLUSÃO}

Com base no que foi dito podemos considerar que atualmente presencia-se em diversas esferas o apelo por ações sustentáveis no mundo. Atos que estejam alinhados em prol da economia, da sociedade e do meio ambiente. Articula-se para a sensibilização da sociedade à causa, já que o sistema em voga ainda é de consumo exagerado, que adota medidas paliativas para lidar com a poluição, baixos salários, má condições de trabalho, descarte inapropriado dos produtos.

O consumo, principalmente no mercado de moda, teve sua expansão no período pós-guerra e a eclosão do fast fashion representa uma tendência da forma de compra, em que a quantidade ganha espaço frente à qualidade e estar na moda por um preço acessível é o mais importante. Porém, para que se obtenha um produto de baixo custo, com proposta de tendências atualizadas e disponível ao consumidor em um curto período de tempo, é necessário fazer escolhas que refletem nas condições dos trabalhadores e na escolha da matéria prima, por exemplo.

Ao considerar uma cultura sedenta por novidade que é significada pelo vestuário que utiliza, têm-se um enorme mercado disponível para as empresas, principalmente as grandes, que podem reduzir ainda mais os seus custos pela quantidade produzida dentro da proposta do fast fashion.

Com relação ao conforto como um valor, baseado em apropriadas medidas antropométricas, pode-se dizer que no Brasil, devido à heterogeneidade do biótipo populacional, tais fatores são questionados e passam a adquirir caráter de diferenciação na hora da compra. Neste sentido, Feghali, Schmid e Lima (2008) comentam que negócios dentro de nichos estratégicos, isto é, em segmentos que não 
são atendidos pelas grandes marcas de varejo, possuem vantagem pois são muito procurados pelo consumidor alvo.

Apesar da ideia do slow fashion ser de um sistema e não apenas de um nicho de mercado, pode-se pensar como algo a ser explorado estrategicamente dentro de um segmento sustentável. Desse modo, atinge-se consumidores que estão dispostos a pagar o valor cabível para a confecção de um produto que não só reavalia sua cadeia produtiva, mas também apresenta um produto com valor agregado. É difícil imaginar uma mudança radical em nível global do sistema produtivo de moda, principalmente se considerar as variações de acesso à renda em países em desenvolvimento. Entretanto, é viável cogitar uma adesão gradativa à um modelo de negócio como ocorreu com a alta costura e o prêt-à-porter no passado.

Em algum momento, pode-se pensar que o trabalho manual proposto pela alta costura esteja em consonância com o slow fashion. Todavia, vale ressaltar, que as algumas peças disponíveis no segmento do fast fashion são inspiradas ou réplicas das criações de grandes marcas e maisons que se apropriam das tendências de moda. Ou seja, esse novo sistema de moda possui uma proposta completamente inovadora em comparação à perspectiva atual.

Do ponto de vista mercadológico, há diversos nichos a serem explorados devido às possibilidades que o vestuário proporciona na área de estilo, textura, modelagem. Entretanto, para que esses nichos sejam explorados é necessário o amadurecimento de algumas áreas a fim de atender adequadamente o consumidor. As fragilidades do estudo antropométrico brasileiro se apresentam como limitações para o desenvolvimento de modelagens mais ajustadas quando se utiliza da produção em larga escala.

A proposta de Bazán et al (2010) pode ser interessante por abordar a regionalização da aferição de medidas. Como se trabalha com foco em grupos determinados, pode-se acreditar que um universo de pesquisa reduzido possa contribuir para o entendimento daqueles que estão nos percentis extremos. Há também que se considerar que na realidade brasileira a geração de dados é muito importante para que se abasteça sistemas de informação já existentes como as normas da ABNT. Daí a necessidade de se desenvolver este tipo de estudo.

$\mathrm{E}$, ao se pensar em uma abordagem local, pode-se imaginar uma correlação com o slow fashion. Uma tabela de medidas local vai de encontro com a proposta de mercado sustentável e que visa atender um público com consciência e responsabilidade. Então, além do fator inovador do próprio negócio, em que há um enfoque para a qualidade, durabilidade e humanização do sistema, há sobretudo a possibilidade de oferecer maior conforto ao usuário por meio de estudos de usabilidade baseados nas corretas medidas antropométricas, com o consumidor do produto final. Vale enfatizar que este representa um universo reduzido e de maior facilidade de medição.

A proximidade dos agentes do sistema produtivo apresentado pelo slow fashion traz ganhos do ponto de vista da validação do produto pelo usuário. 0 consumidor ter a oportunidade de interagir com o sistema é muito importante para que se produza peças mais "interessantes" do ponto de vista de quem vai comprar.

O enfoque do presente artigo foi estabelecer uma correlação entre o slow fashion e o papel da análise antropométrica voltada ao usuário, visando agregar valor 
ao produto final, por meio do incremento da modelagem baseada no conforto. Este valor seria o referencial para o desenvolvimento do produto.

No desenvolvimento do trabalho se percebeu a possibilidade de ser explorado, em estudos futuros, uma verificação da utilização dos canais de marketing por empresas slow fashion, que é uma ideia em desenvolvimento no Brasil. Além disso, pode-se aprofundar, junto às empresas que atuam no sistema slow fashion, a relação com o cliente baseado na usabilidade do produto oferecido. Neste caso poderiam ser explorados outros elementos da usabilidade do produto de moda.

\section{REFERÊNCIAS}

BAZÁN, Aline Aristides et al. Antropometria para a confecção - dados de Cianorte e região. Gepros: Gestão da Produção, Operações e Sistemas, Bauru, v. 4, n. 5, p.61-77, dez. 2010.

FABRI, Hélcio Prado; RODRIGUES, Luan Vallotto. Slow fashion: perspectivas para um futuro sustentável. In: Colóquio de Moda, 11., 2015, Curitiba. Anais Colóquio de Moda. 2015. Disponível em: <http://www.coloquiomoda.com.br/anais/anais/11Coloquio-de-Moda_2015/COMUNICACAO-ORAL/CO-EIXO8-SUSTENTABILIDADE/CO-8SLOW-FASHION.pdf>. Acesso em: 06 maio 2016.

FEGHALI, Marta Kasznar; SCHMID, Erika; LIMA, Vera. O ciclo da moda. Rio de Janeiro: Ed. SENAC, 2008. $166 \mathrm{p}$.

FLETCHER, Kate. Slow fashion. 2007. Disponível em: <http://www.theecologist.org/green_green_iving/clothing/269245/slow_fashion.html >. Acesso em: 06 maio 2016.

FLETCHER, Kate. Fashion and Sustainability FAQs. 2012. Disponível em: <http://katefletcher.com/fashion-and-sustainability-faqs/>. Acesso em: 06 maio 2016.

GIL, Antonio Carlos. Como elaborar projetos de pesquisa. 4. ed. São Paulo: Atlas, 2002. $175 \mathrm{p}$.

KOTLER, Philip; KELLER, Kevin Lane. Administração de marketing. 14. ed. São Paulo: Pearson Education do Brasil, 2012, 765 p.

LIPOVETSKY, Gilles. $O$ império do efêmero: a moda e seu destino nas sociedades modernas. São Paulo: Companhia das Letras, 1991. 294 p.

PHELAN, Hayley. The Slow Fashion Movement: 10 Brands That Are Doing it Right. 2012. Disponível em: <http://fashionista.com/2012/12/the-slow-fashion-movementwhat-it-is-and-the-10-brands-that-are-doing-it-right\#1>. Acesso em: 06 maio 2016.

PORTER, Michael E. Estratégia competitiva: técnicas para análise de industrias e da concorrência. 5. ed. Rio de Janeiro: Campus, 1991. 362 p.

RECH, Sandra Regina. Cadeia produtiva da moda: um modelo conceitual da análise da competitividade no elo confecção. Florianópolis, 2006. 282 f. Tese (Doutorado) Universidade Federal de Santa Catarina, Centro Tecnológico. Programa de PósGraduação em Engenharia de Produção.

SILVEIRA, Icléia. Usabilidade do Vestuário: Fatores Técnicos/Funcionais. Moda Palavra E-periódico, Rio de Janeiro, v. 1, n. 1, p.21-39, jul. 2008. 
The True Cost. Direção de Andrew Morgan. Roteiro: Andrew Morgan. [s.I]: Untold Creative, 2015.

TILLEY, Alvin R. As medidas do homem e da mulher: fatores humanos em design. Porto Alegre: Bookman, 2005. 104 p. 